\title{
Nipple Shields
}

Mothers have used nipple shields for centuries for various breastfeeding issues and problems. Shield use has become controversial, but many clinicians recommend the use of nipple shields under varying circumstances despite the absence of any professionally peer-reviewed or generally agreed-upon guidelines, protocols, policies, or clinical algorithms. Judicious use of nipple shields can salvage the breastfeeding process, and most mothers have found them to be helpful. However, some mothers and studies have reported problems with shields. There remain many questions regarding the effect of nipple shield use on infant feeding behaviors relative to the imprinting that may be affected by presenting a superstimulus to an infant during a sensitive or critical period of time. This raises more questions than answers.

Keywords: nipple shield use, infant feeding behaviors, breastfeeding, imprinting

A nipple shield is an appliance placed over the maternal nipple/areola complex prior to breastfeeding that is often used to aid the infant in latching to the breast. Nipple shield use by breastfeeding mothers has been mentioned in the medical literature since the 1500s (Fildes, 1986). Early shields made from pewter, tin, wood, silver, ivory, horn, glass, and even lead were used to evert flat nipples and to prevent and treat sore or cracked nipples (Fildes, 1986). This was followed by shields made from rubber in the 20th century, then from thin latex, and now with current shields manufactured from silicone. Even though breastfeeding mothers have used some form of nipple shield for centuries, the use of nipple shields remains a controversial topic among lactation professionals (Table 1).

This controversy was probably influenced by older studies that reported significantly reduced milk transfer while using nipple shields (Amatayakul et al., 1987; Auerbach, 1990; Woolridge, Baum, \& Bruett, 1980). Nipple shields in these studies were made from thick rubber or latex which could have inhibited oxytocin release because of the blockage of sensory input from the nipple/areolar complex. Sucking parameters might also have been altered. The ability to generate sufficient vacuum or deflect the shield enough to remove milk from the breast may have further compromised milk transfer. Nevertheless, healthcare professionals currently recommend shields frequently in their practice for various reasons (Table 2) such as flat nipples, sore nipples, latch difficulty, prematurity, oversupply, upper airway disorders, breast refusal, oral

1. Marshalact@gmail.com anomalies, and transitioning an infant from the bottle to the breast (Chow et al., 2015). This is so despite the absence of any professionally peer-reviewed or generally agreed-upon guidelines, protocols, policies, or clinical algorithms for nipple shield use (Eglash, Ziemer, \& McKechnie, 2010).

\section{Foundation of Evidence for Nipple Shield Use}

Studies have looked at several parameters regarding nipple shields such as maternal physiological responses,

\section{Table 1. What Shields Can and Cannot Do}

Shields can

Therapeutically supply oral stimulation that an infant cannot obtain from the mother's nipples because of inability to latch or transfer milk Create a nipple shape in the infant's mouth Compensate for weak infant suction

Present a stable nipple shape that remains during pauses in sucking bursts

Maintain the nipple in a protruded position

Affect the rate of milk flow

Shields cannot

Correct milk transfer problems or weight gain if the mother has inadequate milk volume

Fix damaged nipples if the cause is not discovered and remedied

Replace skilled intervention and close follow-up 
Table 2. Common Situations Where Nipple Shields Have Been Used

Latch difficulty

Nipple anomalies (flat, retracted, fibrous, inelastic)

Mismatch between small infant mouth and large nipple

Infant from heavily medicated mother

Birth trauma (vacuum extraction, forceps)

Oral aversion (vigorous suctioning)

Artificial nipple preference (pacifiers, bottles)

To transition an infant from bottle to breast

Infant with weak or disorganized suck

(slips off nipple, preterm, neurological problems)

Infant with high or low tone

Overactive letdown reflex

Delay in putting infant to breast

To allow supplementation at the breast

by running a tube under or next to the shield

Oral cavity problems

Cleft palate

Channel palate (Turner syndrome, formerly

intubated)

Bubble palate

Lack of fat pads (preterm, small for gestational age)

Low-threshold mouth

Poor central grooving of the tongue

Micrognathia (recessed jaw)

Upper airway problems

Tracheomalacia

Laryngomalacia

Damaged nipples

Sore, cracked, or macerated nipples

Areolar eczema, weeping areolar eczema, or other dermatological issue

When all else fails and the mother states she is going to quit breastfeeding the outcome with preterm infants, infant weight gain, the effect on breastfeeding duration, mothers' own experiences, and health professionals' experiences.

\section{Maternal Physiological Responses}

Blood samples were collected in two studies before, during, and after breastfeeding to ascertain whether prolactin and cortisol levels varied between shield use and no shield use (Amatayakul et al., 1987; Chertok, Schneider, \& Blackburn, 2006). There was no significant difference in hormone levels with or without a nipple shield. These results would suggest that a thin nipple shield does not interfere with the feedback loop between sensory input to the nipple and the connection to the pituitary gland where prolactin is manufactured and released.

\section{Breastfeeding Outcomes With Preterm Infants}

Two small studies looked at the breastfeeding performance of preterm infants ranging in age from 33 to 39 weeks' gestation (Clum \& Primomo, 1996; Meier et al., 2000). These infants had difficulty latching to the breast, slipped off of the nipple after latching, or fell asleep following latch. All of the infants consumed more breast milk when the shield was in place compared with no shield. Judicious shield use with preterm infants could compensate for the less mature feeding behaviors typical of preterm infants such as weak intraoral vacuum and short ineffective sucking bursts. The shield creates and maintains a firmer nipple shape in the infant's mouth and does not retract during pauses or when the infant slips off the nipple. This avoids the infant having to continuously engage in relatching attempts which do not result in milk transfer and could tire out the infant. Milk is obtained through the shield even with minimal suction because weak suction is typical of preterm and late preterm infants. The mechanism that allows better milk transfer may be related to the possible production of negative pressure within the shield's reservoir which allows milk to accumulate and be immediately available with any amount of vacuum application (Meier et al., 2000). The shield tip may be too stiff (Zimmerman \& Barlow, 2008) for many preterm infants to deflect and remove milk through compression.

\section{Infant Weight Gain}

Infant weight gain did not appear to be compromised by the use of nipple shields. Weight gains were measured out to 4 months of age and appeared to be appropriate in two studies of mothers using nipple shields for various reasons (Bodley \& Powers, 1996; Chertok, 2009). 


\section{The Effect of Nipple Shields on Breastfeeding Duration}

Most studies either did not look at risks of weaning when using a nipple shield or did not report premature weaning as a negative outcome of shield use. One study found a higher rate of early weaning among a group of mothers who used artificial nipples, including nipple shields, compared with mothers who offered the breast exclusively (Pincombe et al., 2008). Shield use was begun during the initial hospital stay following delivery. In a study of 4,815 breastfeeding mothers, it was found that $22 \%$ used a nipple shield during the beginning breastfeeding timeframe and $7 \%$ used a shield for the entire breastfeeding experience (Kronborg, Foverskov, Nilsson, \& Maastrup, 2016). Use of a nipple shield during the entire breastfeeding experience in this study was associated with more than three times higher odds of exclusive breastfeeding cessation before 17 weeks postpartum. Using a nipple shield only during the early start to breastfeeding resulted in 63\% higher odds of ending exclusive breastfeeding before Week 17 .

Mothers using a nipple shield more frequently in this study were less experienced in breastfeeding (primiparous), were younger, had a lower education level, and demonstrated a higher body mass index. These are all characteristics that are well known to be associated with a shorter breastfeeding duration. These groups of mothers need expert support in the process of learning to breastfeed beyond just the use of a nipple shield. It is important that mothers using nipple shields are followed closely by skilled lactation providers (such as one with the IBCLC credential) because breastfeeding durations may be prolonged by the combination of judicious shield use and skilled lactation care (Ekström, Abrahamsson, Eriksson, \& Mårtensson, 2014).

\section{Mothers' Descriptive Experiences of Using Nipple Shields}

Most mothers reported positive experiences in most of the studies that looked at maternal satisfaction with nipple shield use. Nipple shields appear to help many mothers who might otherwise abandon breastfeeding (Hanna, Wilson, \& Norwood, 2013). Some mothers discontinued shield use because they did not find them helpful. Other complaints included such things as the shield tended to fall off of the breast, it was inconvenient, messy, the infant took in too much air or depended on the shield, the shield exacerbated leaking, or the shield was uncomfortable especially after the onset of copious milk production (Bodley \& Powers, 1996; Brigham, 1996; Chertok, 2009; Chertok et al., 2006; Powers \& Tapia, 2004).

\section{Health Professionals' Experiences and Attitudes Toward Nipple Shields}

A survey describing nipple shield use among 490 breastfeeding health professionals reported that $92 \%$ used nipple shields in their practice (Eglash et al., 2010) despite the lack of large prospective trials on the safety and efficacy of shield use (McKechnie \& Eglash, 2010). Most of the respondents to this survey (73\%) expressed concern regarding the lack of appropriate follow-up for mothers using nipple shields. Nipple shields are readily available to mothers in the retail marketplace and could provide false reassurance of breastfeeding progress or preclude mothers from contacting professional lactation services (Eglash et al., 2010).

Many of the studies on nipple shields are small observational studies and may not have sampled sufficiently large numbers of mothers or may not have included certain outcomes in their methodology. For example, mastitis was noted in one study as a negative outcome in $12 \%$ of mothers who were still using nipple shields at 3 months (Nicholson, 1993) but may not have been examined as a complication in other studies when it should have been. Two thorough literature reviews of nipple shield use concluded that what is published in the current literature does not support many of the practices regarding why and how nipple shields are used (Chow et al., 2015; McKechnie \& Eglash, 2010).

Although the literature may not unconditionally support nipple shield use, clinically, it has been shown to be a useful tool. This dichotomy presents somewhat of a dilemma to practicing clinicians. On the one hand, nipple shields can provide a quick and often "effective" intervention, but little is known regarding their effect on infant feeding behaviors relative to the imprinting that may be affected by presenting a superstimulus to an infant during a sensitive or critical period. Imprinting in infants could be defined as a stage of neurobehavioral development in which the mother is recognized through oral tactile memory (Mobbs, Mobbs, \& Mobbs, 2015). A superstimulus or a supernormal stimulus (such as the nipple shield) is a term evolutionary biologists use to describe any stimulus that elicits a response stronger than the stimulus for which it evolved. The exaggerated traits (stiffer, longer, bigger) experienced with the nipple shield could influence preference for the artificial nipple over the real thing.

In developmental biology, a critical period is a maturational stage when the brain and nervous system are especially sensitive to certain environmental stimuli. Failure to experience the appropriate stimulus during this period may make it more difficult to learn a particular skill later on. 


\section{Considerations of What We Wish We Knew}

Much of what has been reported about nipple shields has left more questions than answers.

\section{Question: Does the Use of a Nipple Shield Alter Sucking Dynamics or Affect Oral Tactile Learning?}

Woolridge et al. (1980) noted an increased sucking rate and more pauses between sucking bursts when a thick rubber shield was in place. Other nipple shield studies did not assess sucking dynamics over any type of a shield. It is known that variations in pacifier stiffness can alter nonnutritive burst-pause sucking patterns in preterm infants (Zimmerman \& Barlow, 2008). It is not known whether burst-pause sucking dynamics are altered in full term infants during nutritive sucking on nipple shields of varying stiffness. The teat portion of a nipple shield is much stiffer than the maternal nipple, may be larger than the mother's nipple, presents a different texture to the infant, and does not deflect and elongate like a human nipple. The texture of an oral object in the infant's mouth can modulate the sucking instructions from the suck central pattern generator. When presented with either a smooth or a textured pacifier, healthy term infants were seen to reorganize and change their nonnutritive sucking pattern depending on the texture presented to them (Oder, Stalling, \& Barlow, 2013).

The act of sucking on a nipple shield produces sensory cues from Merkel cells that line the lip vermillion and buccal mucosa. These oral mechanoreceptors encode specific information regarding such features as the shape, texture, curvature, and edges to create a neural image of the object in the infant's mouth. The brain then modulates the timing and output from the suck central pattern generator according to the cues it has received from the Merkel cells.

Central pattern generators are located in the brain stem reticular formation and are composed of networks of interneurons that produce rhythmic motor patterns such as breathing, walking, and sucking (Marder \& Bucher, 2001). The oral tactile input from the Merkel cells is a learned form of perceptual recognition which governs the imprinting process. If the Merkel cells have encoded a nipple shield rather than the maternal nipple during a critical window of learning, would it then alter how the infant sucks in the absence of a shield? Should a shield be avoided during the early hours and days so that the Merkel cells encode the maternal nipple as the imprinted object to avoid altering suck instructions from the suck central pattern generator? If a shield is needed, should it then be offered after the (unknown) critical period? Because nipple shields do not always result in a successful outcome, could faulty suck imprinting contribute to the lack of resolution of the breastfeeding problem? Do different sizes and shapes of nipple shields alter sucking patterns? Does displacement of the normal imprint from the mother's nipple warrant closer monitoring of infant weight gain during shield use and following discontinuance of a shield? Do many infants simply relearn a different manner of sucking when returning to the maternal nipple, whereas a few infants may not be able to do so?

\section{Question: Could Nipple Shields Contribute to or Exacerbate Nipple Pain or Other Conditions Such as Mastitis?}

Although nipple pain or damage may be a common reason for the use of a nipple shield, some mothers continue to experience persistent nipple pain even with the shield in place. Some infants have been reported to create a high intraoral vacuum during breastfeeding, higher than reference values (McClellan et al., 2008) which may lead to nipple pain. A nipple shield may reduce the amount of vacuum applied to the nipple (Perrella, Lai, \& Geddes, 2015).

A case study of persistent nipple pain with a shield revealed that the infant exerted very high intraoral vacuum causing blisters on the nipple tip from the nipple epithelium being drawn through the holes of the shield (Perrella et al., 2015). One intervention in this study that was used to alleviate the pain was to switch from a $24-\mathrm{mm}$ shield to a $28-\mathrm{mm}$ shield to reduce the pressure inside the shield teat by increasing the volume of space surrounding the nipple. Changing to a larger shield size may help mothers who continue to experience nipple pain when using a shield. Many mothers simply use whatever shield is given to them or purchased by them without any consideration or follow-up regarding proper size or if a too small shield builds up too much vacuum in the small space of the shield teat and serves as a contributor to persistent nipple pain. Because nipples expand when using a breast pump, they might also expand when using a nipple shield. Should mothers have two sizes of nipple shields to account for nipple expansion or build-up of vacuum within the shield teat?

One study reported a $12 \%$ rate of mastitis in mothers who were still using a nipple shield at 3 months postpartum (Nicholson, 1993). Could long-term continuous use of a nipple increase the risk of mastitis? A large study on determinants of mastitis showed that mothers who used nipple shields had a two-fold increased risk of developing mastitis compared to women who reported no nipple shield use (Cullinane et al., 2015). This could be partially accounted for if these mothers were using a shield because of nipple trauma which correlated with 
the development of mastitis. Would shield use increase the risk of mastitis because milk flow might be reduced because of the confines of the shield teat? Would milk back up in the breast causing milk stasis? Would back pressure occur during the milk ejection reflex because of a lack of egress for the milk under pressure? Would it be important for mothers who use a shield to be advised to massage and compress the breast periodically during a feeding to prevent or ameliorate pockets of retained milk or plugged milk ducts?

\section{Question: How Should a Shield Be Selected} Based on Size, Shape, Stiffness, Thickness, or Other Mechanical Properties of the Product?

Nipple shields come in many sizes (Table 3 ) and several different shapes. Nipple shield sizes range from $16 \mathrm{~mm}$

\begin{tabular}{|c|c|c|}
\hline Product & Size & $\begin{array}{l}\text { Number } \\
\text { of Holes }\end{array}$ \\
\hline Avent & $21 \mathrm{~mm}$ & 3 \\
\hline $\begin{array}{l}\text { Medela } \\
\text { Standard } \\
\text { Contact }\end{array}$ & $\begin{array}{l}16 \mathrm{~mm} \\
20 \mathrm{~mm} \\
24 \mathrm{~mm} \\
16 \mathrm{~mm} \\
20 \mathrm{~mm} \\
24 \mathrm{~mm} \\
\end{array}$ & 4 \\
\hline Ameda & $24 \mathrm{~mm}$ & 5 \\
\hline Ardo & $\begin{array}{l}20 \mathrm{~mm} \\
24 \mathrm{~mm}\end{array}$ & 4 \\
\hline Mamivac & & 4 \\
\hline Conical & $\begin{array}{l}18 \mathrm{~mm} \\
20 \mathrm{~mm} \\
28 \mathrm{~mm} \\
\end{array}$ & \\
\hline Cherry shaped & $\begin{array}{l}18 \mathrm{~mm} \\
22 \mathrm{~mm} \\
\end{array}$ & \\
\hline Nuk & $\begin{array}{l}20 \mathrm{~mm} \\
24 \mathrm{~mm}\end{array}$ & 4 \\
\hline Lansinoh & $24 \mathrm{~mm}$ & 4 \\
\hline Dr. Brown's & & 13 \\
\hline LOVE MY & $\begin{array}{l}16 \mathrm{~mm} \\
20 \mathrm{~mm} \\
24 \mathrm{~mm}\end{array}$ & 4 \\
\hline
\end{tabular}

to $28 \mathrm{~mm}$. Mothers' nipple diameters range in size from less than $12 \mathrm{~mm}$ at their base to greater than $23 \mathrm{~mm}$ at their base (Ramsay, Kent, Hartmann, \& Hartmann, 2005; Wilson-Clay \& Hoover, 2013). Just as mothers' nipples vary in length, so too can nipple shield teats. There are no agreed-upon guidelines for selecting the proper size shield for a mother. The height of the nipple portion of the shield should not exceed the length of the infant's mouth from the juncture of the hard and soft palates to lip closure (Wilson-Clay \& Hoover, 2002). If the height of the teat of a shield is greater than this length, the infant's jaw closure and tongue compression will fall on the shaft of the teat and not over the breast. Too small a shield can pinch the nipple, increase vacuum within the teat, and contribute to persistent nipple pain especially if the nipple swells during sucking. Too long a shaft of the teat can cause an infant with a small mouth to gag, whereas too short a teat may result in an infant that can only place the teat in the anterior portion of the mouth contributing to a shallow latch and impedance of milk transfer. The shape of the teat can vary from a perfectly straight teat to teats of varying slopes to a rounded or cherry-shaped teat (Figure 1).

The conical-shaped teat is typical of most nipple shields and could vary in its slope. The cherry-shaped shield from Mamivac could be helpful for an infant with sucking difficulties such as tongue-tie. The rounded shape may offer an easier latch for some infants because of a curve that may prevent the infant from slipping down the slope of a conical-shaped shield. Would the shape of the shield cause the infant's mouth conformation to be stored in

Figure 1. Conical-and cherry-shaped nipple shields.

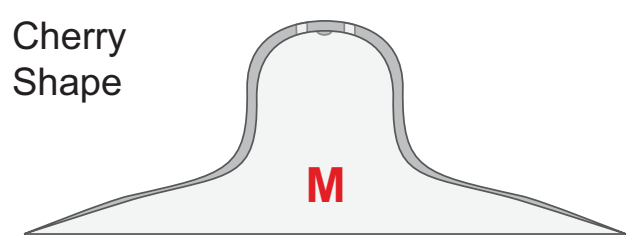

Medium D $=22 \mathrm{~mm}$

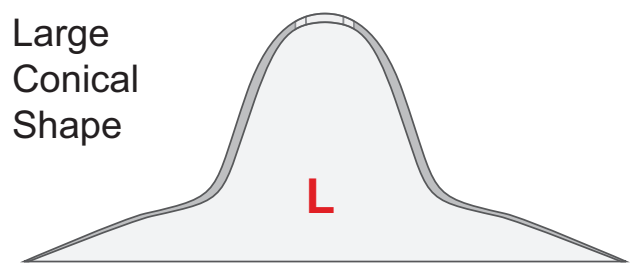

Large $D=28 \mathrm{~mm}$ 
the suck central pattern generator and then be repeated when presented with the mother's nipple minus the shield? Each shield may vary in thickness, stiffness, and the amount of compression it takes to deflect the shield.

In a study of pacifiers, it was shown that one particular pacifier could be seven times stiffer than others made by the same manufacturer (Zimmerman \& Barlow, 2008). Are some nipple shields thicker and stiffer than others? Some manufacturers make a nipple shield with a cut out shape to allow more skin contact between the mother and infant. Because most nipple shields cover the part of the areola that contains the glands of Montgomery, might nipple shields either mask or eliminate the infant's use of olfaction to locate and identify the mother's specific odor? How important are the pheromones of the mother? Would a nipple shield with a cut out section present better olfaction guidance to the breast? Manufacturers claim that the shields are odorless and tasteless, but are they? How can a shield be best recommended when there are no guidelines for choosing the shape, size, texture, thickness, or stiffness of a particular shield for a particular problem?

\section{Question: Does Long-Term Use of a Silicone Nipple Shield Expose the Infant to the Release of Silicone Plasticizers From the Product?}

The release of medium-weight silicones from silicone pacifiers and artificial nipples was shown to occur in a study that quantified silicone release from household objects and baby articles (Gross, 2015). Infants sucking on silicone items may thus be exposed to several tens to more than a hundred micrograms of synthetic silicone polymers. Extrapolated to silicone nipple shields that will be sucked on for many hours, how much silicone release would occur from nipple shields? What is a safe amount of silicone ingestion?

\section{Question: What Is the Best Way to Apply, Use, and Wean From a Nipple Shield?}

Typical application of the shield is to turn it almost inside out, center the teat portion over the mother's nipple, stretch the part of the shield where it joins the brim, press down on either side of the nipple, and smooth out the brim of the shield. This should draw the nipple into the shield so it is immediately available to the infant. To help the shield adhere better, some clinicians will have the mother run the shield under hot water, making it more pliable and perhaps allowing the heat to encourage the milk ejection reflex. It has been shown that warming the flange on a breast pump collection kit enhances the efficiency of milk removal (Kent, Geddes, Hepworth, \&
Hartmann, 2011). The warm nipple shield could enhance the milk ejection reflex, filling the teat with milk so that milk is immediately available to the infant. This would be especially important to a preterm infant or an infant with low tone or other sucking difficulty. If the mother's milk does not let down quickly, the teat can be preloaded with expressed milk by using a periodontal syringe to inject milk into the teat prior to the infant latching on.

The infant should be assessed for correct latch and should not be sucking on just the teat portion of the shield. The brim of the shield should not curl over the infant's mouth or nose. The shield should be washed with hot soapy water and rinsed well after each use. Some mothers will need to pump milk in addition to using the shield if their supply has been compromised by the situation or if the infant requires supplementation.

There is no set time to wean an infant (or mother) from shield use. Some mothers use a shield throughout the entire breastfeeding experience. Mothers start the shieldweaning process simply by encouraging skin-to-skin contact next to the nipple, starting the feed with the shield and then removing it and gradually trying feeds without the shield. The tip of the shield should not be cut off in an attempt to present less and less of the device to the infant. Rough edges may scrape the infant's mouth, and the altered shape and consistency of the shield may not be appropriate to the desired outcome.

\section{Follow-Up}

Following a mother using a shield is important to assure that the infant is latched correctly and transferring milk with frequent weight checks to assure appropriate weight gain. The mother's milk production should be monitored because she may need to pump milk after several feedings each day to assure an abundant supply. Although we are often left with more questions than answers, many mothers have found that nipple shield use salvaged a difficult breastfeeding situation and were pleased with their experience. Nipple shields, like any other breastfeeding tool, should be used judiciously, appropriately, and with sufficient follow-up to assure that the mother's breastfeeding goals are met. Manufacturers should assure that their packaging and website refer mothers to an IBCLC if the product is purchased or being considered for use. Using the most conservative approach, nipple shield guidelines might be offered as in Table 4 .

\section{Conclusion}

The current body of literature on nipple shields could benefit from more research regarding the questions generated by 


\section{Table 4. Conservative Nipple Shield Guidelines}

\begin{tabular}{|c|c|}
\hline Action & Rationale \\
\hline $\begin{array}{l}\text { Recommend a nipple shield if the clinical situation } \\
\text { warrants it. }\end{array}$ & $\begin{array}{l}\text { Not all special situations require a shield. Shield use } \\
\text { may preserve breastfeeding in selected situations. }\end{array}$ \\
\hline $\begin{array}{l}\text { If a nipple shield is required during the initial hospital } \\
\text { stay, allow the infant to feed or attempt to feed at the } \\
\text { breast at least once or twice before introducing a shield. }\end{array}$ & $\begin{array}{l}\text { Allow the infant to imprint on the maternal nipple } \\
\text { first. Shield use during the hospital stay may help } \\
\text { prevent excessive weight loss prior to discharge and } \\
\text { avoid the use of supplemental bottles }\end{array}$ \\
\hline $\begin{array}{l}\text { Recommend the right size and shaped shield as the } \\
\text { situation warrants. Start with a medium-size shield, use } \\
\text { a larger one if the shield pinches, if the maternal nipple } \\
\text { is large, or if there is pain. Use the smallest shield that } \\
\text { gives the best results. A cutout shield may be prudent } \\
\text { for early use to allow olfaction to guide the infant to } \\
\text { the breast. A cherry-shaped shield may be helpful if the } \\
\text { infant has difficulty latching to the conical shield. }\end{array}$ & $\begin{array}{l}\text { Clinicians may need to try a number of different } \\
\text { shields to secure the best fit and outcome. }\end{array}$ \\
\hline $\begin{array}{l}\text { Advise the mother to warm the shield under hot water } \\
\text { prior to application, turn it almost inside out to apply, } \\
\text { hand express colostrum or milk into the teat or use a } \\
\text { periodontal syringe to preload the teat with milk. }\end{array}$ & $\begin{array}{l}\text { Warming helps the shield adhere better and promotes } \\
\text { milk ejection. Proper application allows the maternal } \\
\text { nipple to be drawn into the shield's teat. Milk in the teat } \\
\text { provides immediate availability so that infants with a weak } \\
\text { suck do not become fatigued while initiating milk flow. }\end{array}$ \\
\hline $\begin{array}{l}\text { Have the mother massage and compress the breast } \\
\text { periodically during the feeding. }\end{array}$ & $\begin{array}{l}\text { This may prevent milk stasis, plugged ducts, and } \\
\text { mastitis. }\end{array}$ \\
\hline $\begin{array}{l}\text { Pump following feedings if milk production is low or } \\
\text { the risk for a compromised milk supply is high. }\end{array}$ & $\begin{array}{l}\text { Milk production must be monitored to assure an } \\
\text { abundant supply and that the shield is not contributing } \\
\text { to milk supply reduction. }\end{array}$ \\
\hline $\begin{array}{l}\text { Check to make sure that the shield is properly } \\
\text { applied, that the infant is latched appropriately and is } \\
\text { transferring milk, and that the mother knows how to } \\
\text { clean the shield. Recommend frequent weight checks. }\end{array}$ & $\begin{array}{l}\text { Shield use should not reinforce improper latching. } \\
\text { Milk transfer monitoring is important to assure proper } \\
\text { infant weight gain and an abundant milk supply. }\end{array}$ \\
\hline $\begin{array}{l}\text { Recommend that the mother make an appointment } \\
\text { with an IBCLC for continued follow-up. }\end{array}$ & $\begin{array}{l}\text { Professional follow-up is required for assessing and } \\
\text { monitoring any ongoing problems or issues that } \\
\text { necessitated shield use. }\end{array}$ \\
\hline
\end{tabular}

nipple shield use. Large prospective trials and well-designed mixed methods studies would enable the development of clinical algorithms or protocols that would aid healthcare providers in their clinical practice. Nipple shields can be a useful tool to help preserve the breastfeeding experience, but clinicians and mothers would benefit even more if we had answers to what we wish we knew.

\section{References}

Amatayakul, K., Vutyavanich, T., Tanthayaphinant, O.,

Tovanabutra, S., Yutabootr, Y., \& Drewett, R. F. (1987). Serum prolactin and cortisol levels after sucking for varying periods of time and the effect of a nipple shield. Acta Obstetricia et Gynecologica Scandinavica, 66, 47-51.
Auerbach, K. G. (1990). The effect of nipple shields on maternal milk volume. Journal of Obstetric, Gynecologic, and Neonatal Nursing, 19, 419-427.

Bodley, V., \& Powers, D. (1996). Long-term nipple shield use: A positive perspective. Journal of Human Lactation, 12, 301-304.

Brigham, M. (1996). Mothers' reports of the outcome of nipple shield use. Journal of Human Lactation, 12, 291-297.

Chertok, I. R. (2009). Reexamination of ultra-thin nipple shield use, infant growth and maternal satisfaction. Journal of Clinical Nursing, 18, 2949-2955.

Chertok, I. R., Schneider, J., \& Blackburn, S. (2006). A pilot study of maternal and term infant outcomes associated with ultrathin nipple shield use. Journal of Obstetric, Gynecologic, and Neonatal Nursing, 35, 265-272. 
Chow, S., Chow, R., Popovic, M., Lam, H., Merrick, J., Ventegodt, S., . . P Popovic, J. (2015). The use of nipple shields: A review. Frontiers in Public Health, 3, 236.

Clum, D., \& Primomo, J. (1996). Use of a silicone nipple shield with premature infants. Journal of Human Lactation, 12, 287-290.

Cullinane, M., Amir, L. H., Donath, S. M., Garland, S. M., Tabrizi, S. N., Payne, M. S., \& Bennett, C. M. (2015). Determinants of mastitis in women in the CASTLE study: A cohort study. BMC Family Practice, 16, 181.

Eglash, A., Ziemer, A. L., \& McKechnie, A. C. (2010). Health professionals' attitudes and use of nipple shields for breastfeeding women. Breastfeeding Medicine, 5, 147-151.

Ekström, A., Abrahamsson, H., Eriksson, R.-M., \& Mårtensson, B. L. (2014). Women's use of nipple shields - their influence on breastfeeding duration after a process-oriented education for health professionals. Breastfeeding Medicine, 9, 458-466.

Fildes, V. (1986). Breasts, bottles and babies: A history of infant feeding. Edinburgh, United Kingdom: Edinburgh University Press.

Gross, J. H. (2015). Analysis of silicones released from household items and baby articles by direct analysis in real time-mass spectrometry. Journal of the American Society for Mass Spectrometry, 26, 511-521.

Hanna, S., Wilson, M., \& Norwood, S. (2013). A description of breast-feeding outcomes among U.S. mothers using nipple shields. Midwifery, 29, 616-621.

Kent, J. C., Geddes, D. T., Hepworth, A. R., \& Hartmann, P. E. (2011). Effect of warm breastshields on breast milk pumping. Journal of Human Lactation, 27, 331-338.

Kronborg, H., Foverskov, E., Nilsson, I., \& Maastrup, R. (2016). Why do mothers use nipple shields and how does this influence duration of exclusive breastfeeding? Maternal $\mathfrak{B}$ Child Nutrition. Advance online publication. http://dx.doi.org/10.1111/mcn.12251

Marder, E., \& Bucher, D. (2001). Central pattern generators and the control of rhythmic movements. Current Biology, 11, 986-996.

McClellan, H., Geddes, D., Kent, J., Garbin, C., Mitoulas, L., \& Hartmann, P. (2008). Infants of mothers with persistent nipple pain exert strong sucking vacuums. Acta Paediatrica, 97, 1205-1209.
McKechnie, A. C., \& Eglash, A. (2010). Nipple shields: A review of the literature. Breastfeeding Medicine, 5, 309-314.

Meier, P. P., Brown, L. P., Hurst, N. M., Spatz, D. L., Engstrom, J. L., Borucki, L. C., \& Krouse, A. M. (2000). Nipple shields for preterm infants: Effect of milk transfer and duration of breastfeeding. Journal of Human Lactation, 16, 106-114.

Mobbs, E. J., Mobbs, G. A., \& Mobbs, A. E. (2016). Imprinting, latchment and displacement: A mini review of early instinctual behavior in newborn infants influencing breastfeeding success. Acta Paediatrica, 105, 24-30.

Nicholson, W. L. (1993). The use of nipple shields by breastfeeding women. Australian College of Midwives Incorporated Journal, 6, 18-24.

Oder, A. L., Stalling, D. L., \& Barlow, S. M. (2013). Short-term effects of pacifier texture on NNS in neurotypical infants. International Journal of Pediatrics, 2013, 168459.

Perrella, S., Lai, C. T., \& Geddes, D. T. (2015). Case report of nipple shield trauma associated with breastfeeding an infant with high intra-oral vacuum. BMC Pregnancy and Childbirth, 15, 155.

Pincombe, J., Baghurst, P., Antoniou, G., Peat, B., Henderson, A., $\&$ Reddin, E. (2010). Baby Friendly Hospital Initiative practices and breastfeeding duration in a cohort of first-time mothers in Adelaide, Australia. Midwifery, 24, 55-61.

Powers, D., \& Tapia, V. B. (2004). Women's experiences using a nipple shield. Journal of Human Lactation, 20, 327-334.

Ramsay, D. T., Kent, J. C., Hartmann, R. A., \& Hartmann, P. E. (2005). Anatomy of the lactating human breast redefined with ultrasound imaging. Journal of Anatomy, 206, 525-534.

Wilson-Clay, B., \& Hoover, K. (2002). The breastfeeding atlas (2nd ed.). Austin, TX: LactNews Press.

Wilson-Clay, B., \& Hoover, K. (2013). The breastfeeding atlas (5th ed.). Manchaca, TX: LactNews Press.

Woolridge, M. W., Baum, J. D., \& Drewett, R. F. (1980). Effect of a traditional and of a new nipple shield on sucking patterns and milk flow. Early Human Development, 4, 357-364.

Zimmerman, E., \& Barlow, S. M. (2008). Pacifier stiffness alters the dynamics of the suck central pattern generator. Journal of Neonatal Nursing, 14, 79-86.

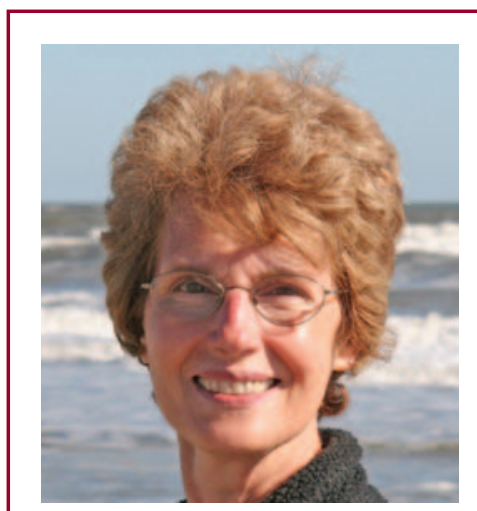

Marsha Walker, RN, IBCLC, has been assisting breastfeeding families in hospital, clinic, and home settings since 1976. Marsha is the executive director of the National Alliance for Breastfeeding Advocacy: Research, Education, and Legal Branch (NABA REAL). As such, she advocates for breastfeeding at the state and federal levels. She served as a vice president of the International Lactation Consultant Association (ILCA) from 1990 to 1994 and in 1999 as president of ILCA. She is a board member of the United States Lactation Consultant Association (USCLA), USLCA's representative to the USDA's Breastfeeding Promotion Consortium, and NABA REAL's representative to the United States Breastfeeding Committee. Marsha is an international speaker and an author of numerous publications including ones on the hazards of infant formula use, code issues in the United States, and Breastfeeding Management for the Clinician: Using the Evidence. 